\title{
LA RESPONSABILIDAD SOCIAL UNIVERSITARIA: ¿DEBER O COMPROMISO?
}

\author{
UNIVERSITY SOCIAL \\ RESPONSIBILITY: DUTY OR \\ COMMITMENT?
}

Isabel Capillo Lucar

deycy1879@gmail.com

\begin{abstract}
RESUMEN
La universidad concebida como una institución de servicio define la Responsabilidad Social Universitaria (RSU) como una política de gestión, que apunta a lograr la calidad ética de sus miembros, mediante la gestión responsable de los impactos que esta genera, debiendo ser asumida con compromiso y responsabilidad, contribuyendo a la sostenibilidad del planeta y asegurando una vida digna para las futuras generaciones. En tal sentido, surge la duda ${ }_{i}$ Es un deber o compromiso?
\end{abstract}

\section{PALABRAS CLAVE}

Universidad, responsabilidad, sociedad, obligación, compromiso, problemática social.

\footnotetext{
ABSTRACT

The university conceived as a service institution defines University Social Responsibility (RSU) as a management policy, which aims to achieve the ethical quality of its members, through the responsible management of the impacts it generates, and must be assumed with commitment and responsibility contributing to the sustainability of the planet and ensuring a decent life for future generations. In this sense, doubt arises. Is it a duty or commitment?
}

\section{KEYWORDS}

University, responsibility, society, obligation, commitment, social problems.
$\mathrm{E}$ 1 año 2007 en el Perú, se puso en marcha la Propuesta Educativa Nacional al 2021, junto con esta se iniciaron diversos movimientos en el sistema educativo. Ya por ese entonces en nuestro país y América Latina mucho antes, se hablaba de un fenómeno denominado Responsabilidad Social Universitaria (RSU), el cual tiene sus raíces en la Responsabilidad Social Empresarial (RSE). Años después, el Ministerio de Educación pone en marcha la nueva Ley Universitaria $\mathrm{n}^{\circ} 30220$, la cual contempla la RSU en el artículo 124 y 125 del capítulo XIII, y sostiene que la RSU es la gestión ética y eficaz del impacto generado por la universidad en la sociedad debido al ejercicio de sus funciones (...), contribuye al desarrollo sostenible y al bienestar de la sociedad.

Además, sostiene que cada universidad es responsable de promover la implementación de la RS, para la cual establece el $2 \%$ de su presupuesto para incentivar y promover el desarrollo de proyectos de RS, incluso señala que la RSU está contemplada como parte de los estándares de acreditación universitaria.

La implementación de estos artículos de la Ley Universitaria, referidos a la RSU, ha generado muchos debates y diferentes puntos de vista, 
coincidiendo en que la universidad debe asumir un rol protagónico dentro de la sociedad. Por tanto, se debe reorganizar de modo tal que se convierta en una organización socialmente responsable y ejemplar, capaz de diagnosticar, proponer y trabajar en función de revertir la variedad de factores que atentan contra la sostenibilidad del mundo en el que vivimos.

Por este motivo es necesario tomar en cuenta que la Universidad, dentro de la globalización, tiene una RS clara, dado que su rol principal es de formar a los futuros profesionales, quienes tendrán que hacer uso de sus conocimientos y capacidades, para enfrentar el desafío de superar las expectativas y demandas que la sociedad exige, de modo que se garantice una vida digna para todos.

Al realizar la revisión de la bibliografía, a través de la búsqueda de información en la base de datos de SciELO y Google académico y a través del empleo de palabras claves como: "Responsabilidad Social" y "Responsabilidad Social Universitaria", "rol de las universidades", "gestión de impactos", etc., publicados en los últimos años, y determinando la pertinencia de la información hallada con el estudio a realizar, fue posible diferenciar diferentes puntos de vista acerca de la concepción que se tiene de Responsabilidad Social Universitaria, pero especialmente atrajeron nuestra atención dos puntos de vista que sostienen que la RSU es un compromiso y la otra que afirma que es un deber, por tanto, nos enfocaremos a precisar dichos aspectos.

Etimológicamente el término responsabilidad, procede del latín responsum que significa responder, obligarse, comprometerse a algo, además está ligada a dos palabras - respuesta y habilidad. En consecuencia, se podría afirmar que la RS, es la habilidad de responder al llamado que viene de la sociedad. Podría entenderse también como la obligación de la universidad frente a la problemática que aqueja a la sociedad, en cuanto a sus problemas medio ambientales, problemas de interrelación económica, cultural, religiosa, e ideológica, desarrollo sostenible, etc., en los cuales la universidad puede intervenir en forma complementaria en respuesta a su rol principal de formación profesional e investigación (Vallaeys, 2014).

Vallaeys (2014), sostiene que cuando nos referimos a la RSU, esta no debe reducirse a un simple compromiso que establezca la universidad con la sociedad, más por el contrario, este debe asumirse como un deber que le otorga a la universidad la posibilidad de trascender desde una existencia e independencia legal egocéntrica hacia una autonomía social compartida.

Siendo vital que la universidad se transforme en una organización, capaz de evaluarse a sí misma $\mathrm{y}$ tome conciencia del papel que asume frente a la sociedad en la que está inmersa.

En tal sentido, es imprescindible formar estudiantes éticos y comprometidos con su sociedad, permitiendo que estos amplíen su visión del futuro al ponerle en contacto con las necesidades de su entorno, lo que les permitirá sensibilizarse y asumir una postura, incluso proyectándose a la comunidad a través de acciones y servicios concretos que promuevan cambios y desarrollo para la misma.

La RS en las universidades debe proponer no solo la mejora social, sino que la Universidad debe sentirse parte de esta, lo que se traduciría en la generación de políticas administrativas, normas académicas y de gestión, además de establecer las estrategias adecuadas orientadas a asegurar la congruencia de todos sus procesos (gestión, docencia, investigación y la extensión universitaria) reflejados en la misión y visión de la institución (Quinte, 2015; Vallaeys, 2014 y Beltrán, Iñigo-Bajo y Mata-Segreda, 2014).

Dichos procesos son: gestión universitaria, orientada a transformar la universidad y convertirla en una pequeña comunidad ejemplar, que administra con transparencia, democracia, equidad, apuntando a la calidad y al desarrollo sostenible. Por tanto, debe orientarse a formar 
personas autónomas, que posean identidad, que sean capaces de construir relaciones solidarias.

La Docencia, que tiene la misión de formar profesionales íntegros, capaces de poner en práctica sus conocimientos y transformar la realidad. Dicho profesional debe poseer una sólida formación científica, dominio pedagógico y alta capacidad moral que le permita impactar positivamente en sus estudiantes, por lo que debe estar capacitado en este enfoque de la RSU (Ayala, 2011).

En tal sentido, la planificación, implementación, ejecución y evaluación curricular debe ser pertinente a la demanda social; por ello, se recomienda utilizar estrategias situadas como el aprendizaje basado en proyectos, que promueven el desarrollo del pensamiento crítico y generan aprendizajes significativos, orientados a la solución de problemas identificados en su contexto. Los perfiles profesionales deben asegurar que los egresados cuenten con conocimientos científicos y técnicos apropiados, éticamente formados y con disposición de servicio a la sociedad, anteponiéndolos frente a cualquier interés personal.

La Investigación, se constituye en una función esencial y obligatoria de la universidad, por tanto, debe producir conocimientos y desarrollar tecnologías adecuadas a lo que requiere la sociedad actual, promoviéndose investigaciones transdisciplinarias, que permitan atacar una problemática desde diferentes ángulos, involucrando a actores internos y externos, académicos y no académicos. La generación del conocimiento, a través de líneas de investigación debe enfocarse y vincularse con la solución de los problemas de su realidad inmediata.

Finalmente, la Proyección social, entendida como la participación que hace la Universidad como parte de la sociedad, involucrándose de manera activa en el desarrollo humano, y apuntando al desarrollo sostenible de la comunidad, lo que se pretende es trabajar de manera articulada los departamentos de investigación y los docentes universitarios implementando proyectos de desarrollo.

La RS en las universidades fue siempre asumida en términos de proyección social y extensión universitaria, pero estas se limitaban a cumplir un rol asistencialista, paternalista, filantrópico, etc. (Ayala, 2011), procurando solo satisfacer o cubrir necesidades en forma momentánea, sin generar un impacto real en la comunidad atendida (Herrera, 2017).

Sin embargo, la RSU va más allá, dado que promueve la creación de comunidades de aprendizaje mutuo, que permitan sensibilizar sobre el rumbo del mundo, de modo que todos (gobierno, agentes sociales, estudiantes, docentes y otros sectores de la sociedad) ejecutemos acciones de RS (Álvarez, 2014; Vallaeys, 2008b, 2014, 2016).

Asimismo, Carranza (2017) afirma que la RSU, exige que todos los actores de la universidad se comprometan, de modo que se garantice que la gestión de los procesos administrativos, educativos, cognitivos y sociales ejecutados sean éticos y transparentes.

Por tanto, se hace necesario que se capacite a los docentes y personal administrativo bajo este enfoque, logrando que se establezca una coherencia permanente entre sus procesos organizacionales, pero sobre todo, debe existir una congruencia entre lo que se dice y se hace, cuidando que todos sus procesos sean transparentes, incluso desde el papel que se compra, hasta el cómo se organiza el plan curricular, alineados, a su vez, con las líneas de investigación de dicha institución (Vallaeys, 2014, 2016).

Por otro lado, tenemos a Casilla y Camacho (2017), quienes afirman que la RSU, al ser un término reciente, cuya conceptualización se encuentra en construcción, pero puede ser asumido como el compromiso organizacional de desarrollar proyectos y experiencias en conjunto con los actores, organizaciones y comunidades 
orientados a solucionar sus necesidades y la construcción de posibilidades para lograr un impacto favorable en el desarrollo humano.

Coincidentemente, López, Zalthen y Cervantes (2016) consideran que la RSU es una política de gestión de calidad ética y moral que busca formar personas con valores y compromisos sociales mediante el logro de las políticas institucionales establecidas como comunidad universitaria.

Las universidades son entes con un valor determinante dentro de la sociedad en que se encuentra inmersa, iniciando y emplazando hacia una mejora de aprendizajes, basándose en el desarrollo de proyectos sociales diversos.

Desde el punto de vista de Ayala (2011), la RSU "se presenta como un desafío a las universidades (...) implica que se comprometan no solo con formar buenos profesionales, sino también en formar personas sensibles con el desarrollo de su país y la inclusión social de los más vulnerables" (p. 1).

Vallaeys (2008b) sostiene que la Comisión Europea define a la RS como un simple compromiso voluntario, y que dista de toda obligación legal; por tanto, dependía únicamente de la buena voluntad de las organizaciones.

A partir de la revisión bibliográfica realizada, se podría considerar que la RSU es un compromiso voluntario y permanente, el cual debe ser asumido por las universidades para cumplir con los objetivos y demandas del presente siglo, tal como lo sostienen Ayala (2011), López, Zalthen y Cervantes (2016) y el Libro verde de la Unión Europea (2001), lo que permitiría a la sociedad observar el grado de compromiso de cada institución universitaria con su comunidad y, de esta manera, evaluar cuánto y hasta dónde puede o está dispuesto a dar, como iniciativa tanto de sus autoridades como de sus docentes, lo que evidenciará la excelencia de dicha universidad, ya que de este modo estaría respondiendo con acciones concretas a las demandas de la sociedad $\mathrm{y}$ el medio ambiente.
Sin embargo, no se puede negar lo que afirma Vallaeys (2016), que "si la RS fuera libre compromiso voluntario no merecería ni siquiera el nombre de responsabilidad, puesto que toda responsabilidad implica el deber de rendir cuentas", además, está contemplado en la Ley Universitaria $\mathrm{n}^{\mathrm{o}} 30220$ y en los estándares de acreditación del SINEACE.

Finalmente, el reto que se tiene hoy es grande, más aún si se asume la definición propuesta por la norma ISO 26000 donde se sostiene que "la Responsabilidad Social de una organización (universidad, empresa, etc.) se responsabiliza por los impactos de la organización hacia la sociedad y medio ambiente".

En este punto, surge la duda, acerca de cómo entiende la universidad el ser responsable no solo de las acciones directas que desarrolla sino también de los impactos que se producen en el planeta, dentro del campo social, condiciones de habitabilidad humana y vida digna para las futuras generaciones (Vallaeys, 2011 y 2014, p. 109).

Preservar el planeta es el gran reto que tenemos que asumir todas las organizaciones y cuanto más, las universidades, por lo que podría trabajarse desde la RSU, partiendo de las aulas universitarias, generándose conciencia sobre lo que implica dicho reto, sensibilizando, proponiendo y ensayando formas de cómo preservar el planeta.

Frente a este incesante aumento de la población, se debe de planificar la reducción de la población mundial, ya que esta es una de las responsables del deterioro planetario y de las metas establecidas para la responsabilidad mundial, dado que la necesidad de recursos genera actividades desordenadas que evitan la gran preocupación que se tiene por el futuro de nuestras sociedades y el planeta.

Por ejemplo, en 1960 la población mundial era de aproximadamente 3500 millones de habitantes, sin embargo, en solo 60 años después, 
hemos llegado a alcanzar los 7000 millones de habitantes.

La World Wildlife Fund (WWF), sostiene que actualmente se viene utilizando el 50\% más de los recursos que la tierra dispone o puede proveernos; lo que implica que nos hemos convertido en una sociedad consumista, que no se preocupa por los daños colaterales ocasionados por nuestra conducta. Incluso se dice que para el 2025 necesitaremos lo que produce dos planetas completos para satisfacer nuestras necesidades.

La situación que se tiene frente a nosotros es grave, es momento que las universidades asuman el rol protagónico que les corresponde, ya no se trata solo de preocuparnos por los impactos que generamos como seres individuales, no somos una isla, somos ahora ciudadanos planetarios $\mathrm{y}$, como tales, debemos de pensar en qué condiciones dejamos el planeta para las futuras generaciones, es el tiempo de que los países y organizaciones dejen de lado sus conflictos e intereses individuales y se enfoquen en lo que realmente es importante.

\section{CONCLUSIONES}

La RS es un deber que le otorga a la universidad la posibilidad de trascender desde una existencia e independencia legal egocéntrica hacia una autonomía social compartida y que apunta a lograr la calidad ética de sus miembros, mediante la gestión responsable de los impactos que esta genera, debiendo ser asumida con compromiso y responsabilidad, contribuyendo a la sostenibilidad del planeta y asegurando una vida digna para las futuras generaciones.

La RSU debe ser implementada por las universidades, dado que está contemplada en la Ley Universitaria $n^{\circ} 30220$ y es considerada como estándar de calidad, con fines de acreditación para el SINEACE.

La RSU exige que la planificación, implementación, ejecución y evaluación curricular sea pertinente; es decir, la universidad debe formar profesionales capaces de resolver los problemas de la sociedad. Por ello, se recomienda utilizar como estrategia de enseñanza, el aprendizaje basado en proyectos, pues ayuda a generar aprendizajes significativos y orientados a la solución de problemas reales.

Es necesario, también, promover las investigaciones transdisciplinarias que permitan atacar una problemática desde diferentes ángulos, involucrando a los actores internos y externos, académicos y no académicos.

Asimismo, la generación del conocimiento, a través de líneas de investigación, debe enfocarse y vincularse con la solución de los problemas de su realidad inmediata. 


\section{REFERENCIAS}

Álvarez, M. F. (2014). Enfoques de la Responsabilidad Social Universitaria (RSU). Universidad. Discrepancias sobre el modelo de Responsabilidad Social.

Ayala García, M. O. (2011). Responsabilidad social universitaria. Realidad y Reflexión, 2011, Año 11, núm. 33, pp. 61-72.

Beltrán-Llevador, J., Íñigo-Bajo, E., MataSegreda, A. (2016). La responsabilidad social universitaria, el reto de su construcción permanente. Revista Iberoamericana de Educación Superior [en línea] 2016, V. [Fecha de consulta: 2 de agosto de 2019]. Recuperado de: http://www.redalyc.org/ articulo.oa? $\mathrm{id}=299132095001$

Carranza, L. A. (2017). Responsabilidad Social Universitaria como estrategia de integración para trabajar en contra del abandono.

Casilla, D. y Camacho, H. (2017). Evaluación de la Responsabilidad Social Universitaria. Opción [en línea], 28 (Setiembre-diciembre). [Fecha de consulta: 2 de agosto de 2019]. Recuperado de: http://www.redalyc.org/ articulo.oa? id=31025702004 ISSN n ${ }^{\circ} 1012$ 1587

Herrera, M. (2017). Responsabilidad social: eje de la transformación de la universidad en la era de la globalización. Universidades, 60(45).

López - Noriega, M., Zalthen - Hernández, L., Cervantes-Rosas, M. (2016). La responsabilidad social universitaria desde la perspectiva del alumno. RaXimhai [en línea] 2016, 12 (Julio-diciembre). [Fecha de consulta: 2 de agosto de 2019]. Recuperado de: http://www.redalyc.org/articulo. oa? $\mathrm{id}=46148194021$ ISSN n $^{\circ}$ 1665-0441

Quinte Villegas, A. (2018). Responsabilidad Social Universitaria.

Vallaeys, F. (2008b). Responsabilidad Social Universitaria: una nueva filosofía de gestión ética e inteligente para las universidades. En Educación Superior y Sociedad, 13(2), septiembre. Caracas: Instituto Internacional de UNESCO para la Educación Superior en América Latina y el Caribe (IESALCUNESCO).

Vallaeys, F. (2011). Ética y RSU: Breve marco teórico de la Responsabilidad Social Universitaria. Recuperado de: http://blog. pucp.edu.pe/blog/eticarsu.

Vallaeys, F. (2014). La responsabilidad social universitaria: un nuevo modelo universitario contra la mercantilización. Revista Iberoamericana de educación superior, 5(12), 105-117.

Vallaeys, F. (2016). Introducción a la responsabilidad social universitaria RSU. Manual de primeros pasos. México: McGraw-Hill Interamericana Editores, Banco Interamericano de Desarrollo. El Manual está disponible en el siguiente enlace: http://idbdocs.iadb.org/wsdocs/ getdocument.aspx?docnum $=35125786$
Fecha de presentación: 27-01-20

Fecha de aceptación: 19-05-20 